\title{
Role and Behavior of Benthic Microbes Able to Degrade Herbicide Atrazine in Naturally Derived Water/sediment Microcosm
}

\author{
KoJI SATSUMA ${ }^{1 *}$, Hiromi TANAKA ${ }^{1}$, KIYOSHI SATO $^{1}$ and YASUHIRO KATO ${ }^{1}$ \\ ${ }^{1}$ Chemistry Division, The Institute of Environmental Toxicology, Uchimoriya-machi 4321, Mitsukaido, Ibaraki \\ 303-0043, Japan
}

(Received May 13, 2002-Accepted September 5, 2002)

In a simple laboratory microcosm constituted of riverbed sediment and its associated water, rapid degradation of herbicide atrazine mainly to cyanuric acid occurred through microbial degradation. To elucidate the role and behavior of microbes involved in atrazine degradation, comparative microcosms constituted of different sediment/water conditions and constitutions were employed. Fluorescence microscopic observation and direct bacterial count by DAPI (4',6-diamidino-2-phenylindole)-staining and CFU (colony forming unit) count by the plate method were also conducted to supplement the comparative study. As a result, planktonic microbes in the aqueous phase appeared not to be responsible for the initial degradation of atrazine, at least during the present experimental period of 70 days. The sediment was found to be important as a source of degrading microbes. However, once the degradation was initiated, the degrading activity in the aqueous phase was maintained without the sediment. Although CFU in aqueous phase increased with time, this increase in cell number seemed not to reflect the degrading activity. Large, glittering and whole particles, supposed to be microbial cells, were observed by DAPI-staining in the aqueous phase under a microscopic field only when active atrazine-degradation occurred. Therefore, they might be involved in the degrading activity.

Key words: atrazine, degradation, benthic microbes, aqueous phase, sediment

To predict the fate of chemicals released into aquatic and terrestrial environments, various laboratory ecosystems (microcosm) have been developed ${ }^{2,10,12,23,33,34)}$. It is generally accepted that microbes play a major role in the degradation of chemicals in such model ecosystems as well as in the natural environment. However, little is known about the behavior of microbes concerned with the degradation of chemicals. The effect of chemicals as physiologically active substances on sediment/water ${ }^{11,26,31,32)}$ or soil ${ }^{9,17,28)}$ microflora has been well documented. However, there are few studies about how xenobiotic-degrading microorganisms act through the growth and metabolic processes. In the present study, we attempted to examine from an ecological aspect atrazine biodegradation using simple-scale, naturally derived sediment/water microcosms. Recently, in

\footnotetext{
* Corresponding author; E-mail: satsuma@iet.or.jp, Tel: +81-29727-4614, Fax: +81-297-27-4609
}

binary phase environments such as sediment/water, microbial communities both attached and free-living have been recognized to be functionally different ${ }^{16,21,30}$. However, to our knowledge, there have been few reports on such topics dealing with xenobiotic-degrading microbes. Therefore, our findings are expected to provide insight into the behavior and ecology of microorganisms involved in the degradation of chemicals released into natural environments.

\section{Materials and Methods}

\section{Sediment and water}

The sediment and associated water was collected in January 2002 at the Tonegawa River, flowing through the southern part of Ibaraki prefecture, Japan. The surface layer of the riverbed sediment was collected up to a depth of $10 \mathrm{~cm}$. The sediment/water sample was stored for 13 days at $4^{\circ} \mathrm{C}$ in the dark until usage. The physical and chemical properties 
of the river water and the sediment were determined. Properties of the sediment are as follows: $\mathrm{pH}$ at $20^{\circ} \mathrm{C}, 6.5$; organic carbon ( $\%$ of dry sediment), 0.03; and texture classified by ISSA method was "Sand". Properties of the river water are as follows: $\mathrm{pH}$ at $20^{\circ} \mathrm{C}, 7.4$; $\mathrm{BOD}(\mathrm{mg} / \mathrm{l})$, 2.2; $\operatorname{COD}_{\mathrm{Mn}}(\mathrm{mg} / \mathrm{l}), 1.7$; suspended solid $(\mathrm{mg} / \mathrm{l}), 1.7$; total nitrogen $(\mathrm{mg} / \mathrm{l}), 5.63$; and total phosphorus $(\mathrm{mg} / \mathrm{l}), 0.13$.

\section{Chemicals}

Atrazine, uniformly labeled with ${ }^{14} \mathrm{C}$ at the $s$-triazine ring ([ $\left.{ }^{14} \mathrm{C}\right]$ atrazine), was used. The compound was synthesized and identified by the Institute of Isotope Co., Ltd. (Budapest). The specific radioactivity of the compound was 6.44 $\mathrm{MBq} / \mathrm{mg}$ and its radiochemical purity was better than $95 \%$. Unlabeled atrazine and all reference compounds were purchased from Wako Pure Chemical Co., Ltd.

\section{Preparation of microcosm}

Triplicate microcosms for a positive control, referred to as PC-1, PC-2 and PC-3, were prepared as follows: To sediment equivalent to $200 \mathrm{~g}$ on a fresh weight basis $(2 \mathrm{~cm}$ in depth) in a wide-mouth glass bottle, the river water $(280 \mathrm{ml})$ was gently added up to about a $10-\mathrm{cm}$ depth. This bottle (microcosm) was then allowed to stand for two weeks at $25^{\circ} \mathrm{C}$ in the dark to stabilize the microflora in the bottle (pre-incubation).

Duplicate comparative microcosms, constituted of sterilized sediment and intact river water, referred to as SS-1 and SS-2, were prepared as follows: Sediment and river water was prepared and pre-incubated in the same manner as microcosm PCs. At the end of pre-incubation, the river water was transferred to another bottle by decantation and then only sediment was autoclaved $\left(121^{\circ} \mathrm{C}, 20 \mathrm{~min}\right)$. The sterile sediment cooled back to ambient temperature was refilled with the river water.

After pre-incubation, $\left[{ }^{14} \mathrm{C}\right]$ atrazine was applied to the aqueous phase of each microcosm at a concentration of 1.0 $\mathrm{mg} / \mathrm{l}$. When applied, co-solvent was not used in order to avoid disrupting the microflora. The application procedure has been described in our previous report $\mathrm{t}^{29}$.

In the case of microcosm PC-3, only the aqueous phase was transferred to another sterile glass bottle by decantation at Day-35. The alkaline-trap described below was then reconnected and incubation continued without sediment. The sediment remaining in the original bottle was subjected to extraction by the procedure described below.

\section{Quantification of radioactive carbon dioxide}

After the application of $\left[{ }^{14} \mathrm{C}\right]$ atrazine to each microcosm system described above, a couple of traps containing $1 \mathrm{M}$ $\mathrm{NaOH}$ were connected to each system (except microcosm $\mathrm{PC}-2)$ to trap radioactive carbon dioxide $\left({ }^{14} \mathrm{CO}_{2}\right)$. Humidified $\mathrm{CO}_{2}$-free air was continuously introduced into the bottle at a flow rate of approximately $2 \mathrm{ml} / \mathrm{min}$ for 70 days. Each bottle (microcosm) with an air-flow-through system continued to stand at $25^{\circ} \mathrm{C}$ in the dark. The $\mathrm{NaOH}$ solution was renewed every week and aliquots of the collected $\mathrm{NaOH}$ solution were analyzed by liquid scintillation counting (LSC) using an Aloka LSC-5100 liquid scintillation counter with Packard ATOMLIGHT ${ }^{\mathrm{TM}}$ scintillation cocktail.

\section{Analysis of metabolites in aqueous phase}

Aliquots of the river water in the bottle were taken at the appropriate time points and analyzed by LSC. The river water was also subjected to HPLC analysis for separation and quantification of $\left[{ }^{14} \mathrm{C}\right]$ atrazine and its degradation products. HPLC analysis was performed with a Shimadzu LC-10AS liquid chromatograph equipped with an ODS column (GLScience INERTSIL ODS-3 4.6×250 mm) using acetonitrile$0.1 \mathrm{M}$ acetic acid (acetonitrile conc.: 10\%/10 min-linear gradient $/ 15 \mathrm{~min}-100 \% / 5 \mathrm{~min})$ as a mobile phase $(1.0 \mathrm{ml} /$ $\min )$ at $35^{\circ} \mathrm{C}$. The reference compounds were detected with a Shimadzu SPD-10A UV detector, whereas the radioactive metabolites were detected with a Packard 525 TR flow scintillation analyzer. Atrazine and its degradation products were determined by comparison with the $R t$ of reference compounds. Atrazine and cyanuric acid in the river water were quantified by peak area integration of the HPLC chromatograms.

\section{Extraction and analysis of radioactivity in sediment}

At the last sampling point (Day-70), incubation was terminated. After the separation of sediment and water, the sediment was extracted serially with $150 \mathrm{ml}$ each of acetone and acetone/0.1 M HCl $(8: 2, \mathrm{v} / \mathrm{v})$. The sediment/solvent mixtures were filtrated through suction and each filtrate was combined (sediment extract). An aliquot of the sediment extract was taken and subjected to LSC analysis for ${ }^{14} \mathrm{C}$-quantification. The extract was then concentrated and subjected to HPLC analysis as described above. The radioactivity in the unextracted residues was quantified by oxidative combustion of the sample using the Aloka ASC-113 automatic sample combustion system. The ${ }^{14} \mathrm{CO}_{2}$ generated by combustion was collected in $7 \mathrm{ml}$ of Packard CARBOSORB ${ }^{\mathrm{TM}} \mathrm{E}$ and was mixed with $12 \mathrm{ml}$ of Packard PARMAFLUOR ${ }^{\mathrm{TM}}$ E+ scintillation cocktail and subjected to LSC. 


\section{Plate counts}

An aliquot of water phase was taken with time (until Day-49) from microcosm PC-1, serially diluted with filtersterilized $(0.22 \mu \mathrm{m})$ water and inoculated on a 100 -fold diluted nutrient agar plate by the conventional pour plate method. In the case of sediment, a sediment suspension was prepared as follows: About $1 \mathrm{~g}$ of surface sediment (dry weight basis, determined accurately afterwards) was taken with time (until Day-49) from microcosm PC-2. After the addition of $10 \mathrm{ml}$ of filter-sterilized water, the sampled sediment was subjected to dispersion treatment ${ }^{20}$ ) with an ultrasonic cleaner (100-W output, $5 \mathrm{~min}$ ). This suspension containing detached microbial cells was then serially diluted and inoculated in the same manner as the water phase described above. Inoculated agar plates were cultured at $25^{\circ} \mathrm{C}$ for 2 weeks followed by enumeration of colonies.

\section{Observation and direct counts by fluorescence microscopy}

Samples for fluorescent microscopy were taken with time (until Day-49) from microcosm PC-1 (aqueous phase) and PC-2 (sediment suspension, see the preceding section). Each sample was diluted 5 (aqueous phase) or 50 (sediment suspension)-fold with filter-sterilized water and was stained with DAPI to a final concentration of $5 \mu \mathrm{g} / \mathrm{ml}$. After more than 30 min of staining, the whole sample was filtered through polycarbonate black filters $(0.2-\mu \mathrm{m}$ pore size). Microbes retained on the filters were observed and enumerated under an epifluorescence microscope (Olympus VANOX AH2-FL) by the conventional method ${ }^{15,19,25)}$. For filtration, a cellulose membrane filter (3- $\mu \mathrm{m}$ pore size) was lapped over each polycarbonate filter to remove large particles and detritus.

\section{Results and Discussion}

\section{Degradation of atrazine and formation of its metabolites}

Figures 1 and 2 show the dissipation of atrazine and the production of cyanuric acid, respectively, in the aqueous phase. Figure 3 illustrates the time course of representative HPLC-radiochromatograms of the aqueous phase in microcosm PC-2.

In microcosm $\mathrm{PC}-1$ and $\mathrm{PC}-2$, rapid degradation of atrazine was initiated after 42 days and all the atrazine was removed from the aqueous phase in up to 56 days. In the sediment extract of PC- 1 , only $0.5 \%$ of applied atrazine was detected at Day-70. On the basis of our previous study ${ }^{29)}$ and experience, rapid degradation of atrazine was usually

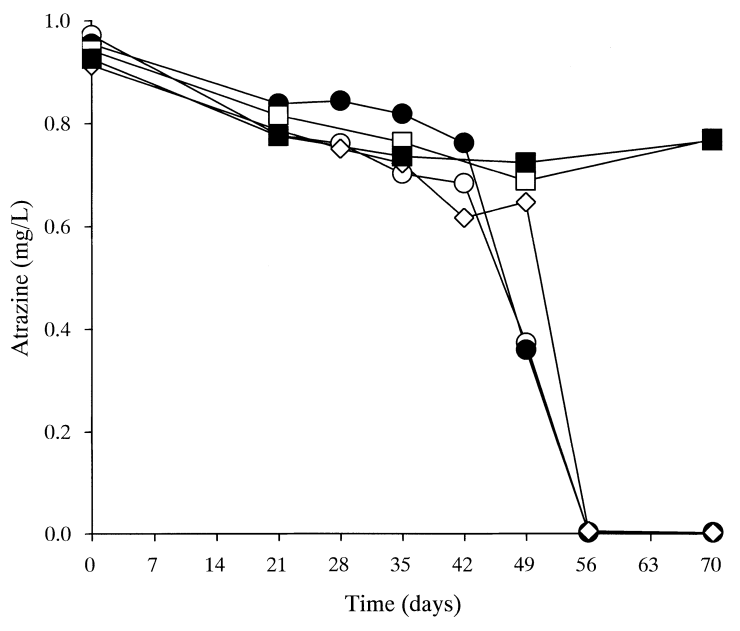

Fig. 1. Dissipation of atrazine in aqueous phase of sediment/water microcosms.

$\bigcirc:$ PC-1, : PC-2, $\diamond:$ PC-3, $\square:$ SS-1 and $\mathbf{\square}:$ SS-2.

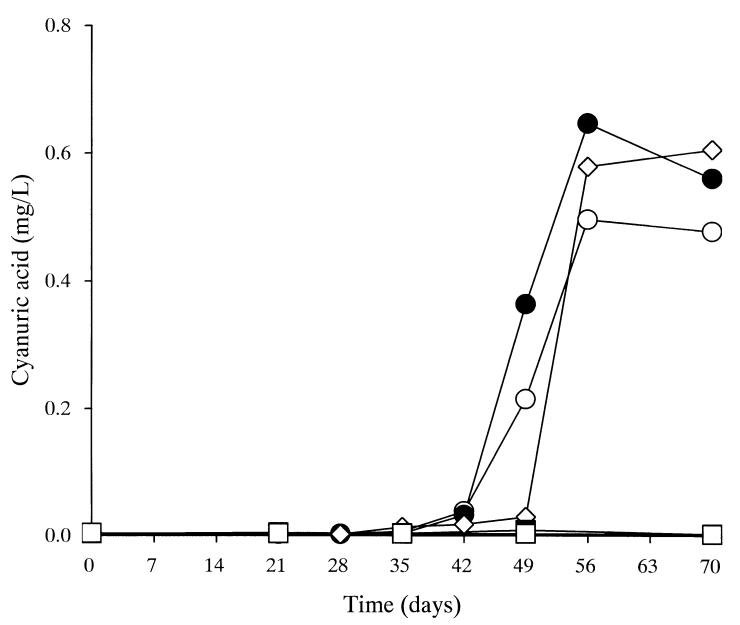

Fig. 2. Formation of cyanuric acid in aqueous phase of sediment/ water microcosms.

$\bigcirc:$ PC-1, $\mathrm{O}$ : PC-2, ৩: PC-3, $\square:$ SS-1 and $\mathbf{\square}:$ SS-2.

initiated at 14 to 28 days after the application of atrazine to river water/sediment microcosms. In the present study, however, the initiation of rapid degradation was delayed regardless of 2-weeks pre-incubation. This difference would be attributed to the collection season of sediment/water samples. The activity and/or population of microbes potentially degrading atrazine appears to be lowered in the present sample, which was collected in midwinter, compared to our previous samples collected in May or September.

Cyanuric acid was produced with dissipation of atrazine and was transiently accumulated in the aqueous phase up to 

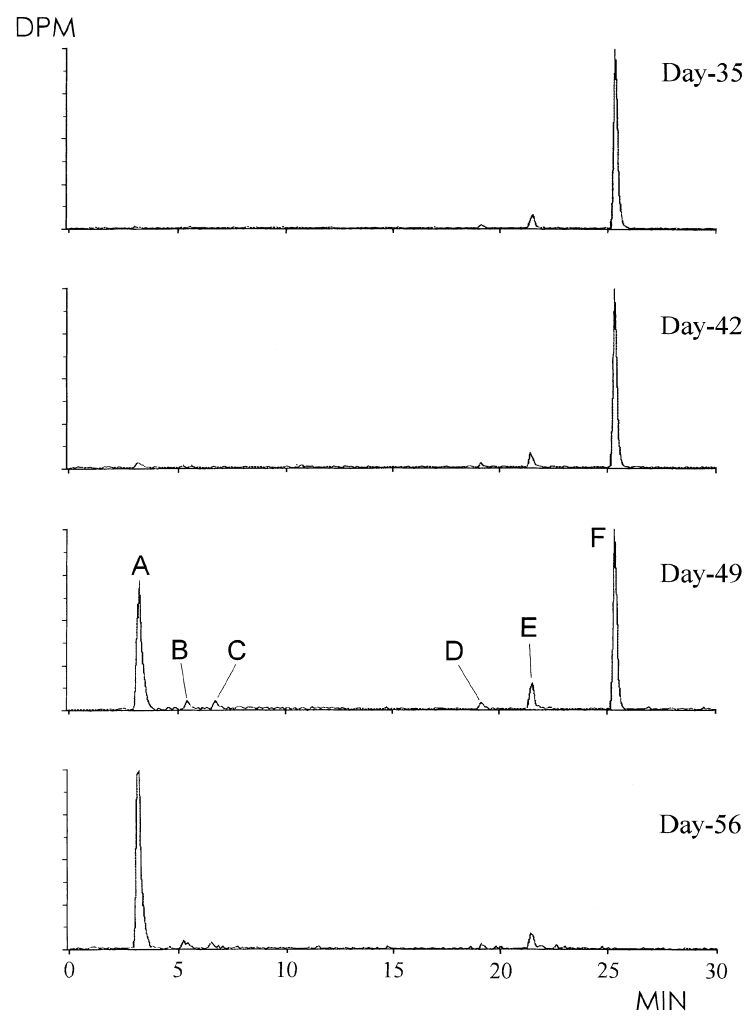

Fig. 3. Representative HPLC radio-chromatograms of aqueous phase of microcosm PC-2.

A: cyanuric acid, 1,3,5-triazine-2,4,6(1H,3H,5H)-trione.

B: deethyl-deisopropylatratrazine, 2-chloro-4,6-amino-s-triazine.

C: hydroxyatrazine, 2-hydroxy-4-(ethylamino)-6-(isopropylamino)-s-triazine.

D: deisopropylatrazine, 2-chloro-4-(ethylamino)-6-amino-striazine.

E: deethylatrazine, 2-chloro-4-amino-6-(isopropylamino)-striazine.

F: atrazine, 2-chloro-4-(ethylamino)-6-(isopropylamino)-striazine.

$0.65 \mathrm{mg} / \mathrm{l}$ (about $65 \%$ of dosage at Day-56, PC-2). Radioactive carbon dioxide was generated accompanied by a decrease of cyanuric acid and it accounted for $6.7 \%$ of dosage at Day-70 (PC-1). As can be seen in Table 1, the recovered radioactivity was rather low in microcosm PC-1 (81.2\%). This is probably due to the volatilization loss of radioactive carbon dioxide included in the sediment phase during extraction. Thus, mineralization of cyanuric acid would have proceeded faster than the apparent estimation. As can be seen from chromatograms of Day-42 to 56 in Figure 3, several degradation products except for cyanuric acid were detected. However, they were produced in small amounts and never exceeded $10 \%$ of dosage. These degradation products have been well studied as microbial metabolites of atrazine $^{1,8,18,22,24,27)}$. Although various metabolic pathways
Table 1. Distribution and balance of applied radioactivity among river water/sediment system 70 days after application of $\left[{ }^{14} \mathrm{C}\right]$ atrazine.

\begin{tabular}{lrcrr}
\multicolumn{1}{c}{ Fraction } & PC-1 & PC-3 & SS-1 & SS-2 \\
\hline & \multicolumn{4}{c}{ \% of Applied- ${ }^{14} \mathrm{C}$} \\
Alkaline Trap & 6.7 & 1.2 & 0.0 & 0.0 \\
Water Phase & 58.2 & 74.1 & 77.8 & 77.5 \\
Sediment Extract & 10.3 & 11.9 a) & 15.7 & 16.1 \\
Unextracted Residues & 6.0 & 4.8 & 2.6 & 2.8 \\
\hline Total ${ }^{14}$ C Recovery & 81.2 & 92.1 & 96.1 & 96.5 \\
\hline
\end{tabular}

a): Sediment was separated from the microcosm and was extracted at Day-35.

have been described, the intermediates are found to be finally degraded to cyanuric acid (Details are summarized in "The University of Minnesota Biocatalysis/ Biodegradation Database": http//www.labmed.umn.edu/umbbd/). Thus cyanuric acid is an important intermediary metabolite of atrazine biodegradation.

\section{Primary degradation of atrazine and role of benthic microbes}

When the sediment was sterilized, in microcosm SS, atrazine degradation was hardly observed. The decrease of the atrazine-concentration in the aqueous phase during the earlier incubation period was probably due to the abiotic absorption by the sediment, as observed in the PC-microcosm. At the last sampling point (Day-70), more than $88 \%$ of applied atrazine still remained in SS-microcosms (aqueous phase plus sediment extract). The result supports the assumption that atrazine-degrading microbes originate from the sediment. The importance of sediment for biodegradation of xenobiotics has been generally accepted ${ }^{2,12)}$. The result described above could be an example for understanding the function of sediment.

On the other hand, in microcosm PC-3, once atrazinedegradation was initiated (when a trace amount of cyanuric acid appeared; corresponding to the chromatogram at Day-35 in Fig. 3), separation of the aqueous phase from the sediment did not affect the primary degradation (Fig. 2).

\section{Mineralization of intermediary metabolite, cyanuric acid}

In microcosm PC-1 and PC-2, cyanuric acid was transiently accumulated and gradually mineralized. The amount of ${ }^{14} \mathrm{CO}_{2}$ produced by mineralization of cyanuric acid would have increased with a longer incubation. It has been reported that a cyanuric acid-mineralizing population frequently occurs in natural environments ${ }^{3,5,6)}$. The ring cleavage path- 


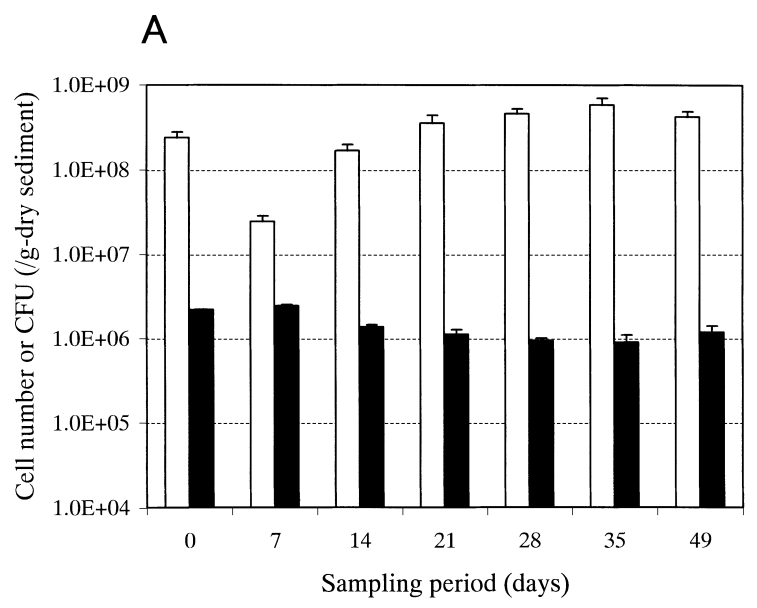

B

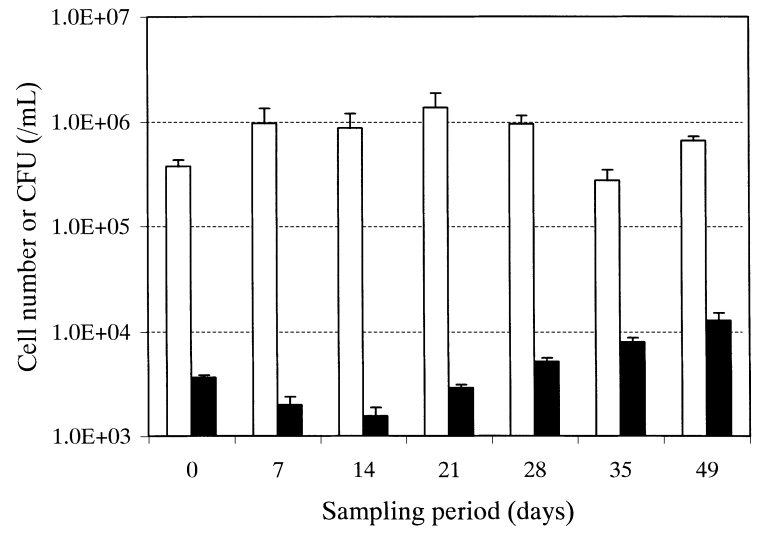

Fig. 4. Variation of microbial population determined by direct microscopic counts $(\square)$ or by plate counts $(\boldsymbol{\square})$

$\mathrm{A}$ : in the sediment of microcosm PC-2.

$\mathrm{B}$ : in the aqueous phase of microcosm PC-1.

Bar indicates standard deviation.

way of cyanuric acid has been also examined ${ }^{4}$. De Souza et $a l .{ }^{7)}$ have reported that two deferent bacterial strains in a microbial consortium sequentially catalyze atrazine side-chain removal and ring cleavage, respectively. In the present investigation, a similar cooperative metabolism may occur.

\section{Microscopic observation and fluctuation of total cell counts and $\mathrm{CFU}$}

Figure 4 shows the time course of change in DAPI-direct counts and CFU in the sediment surface of PC-2 (A) and in the aqueous phase of PC-1 (B). In the sediment phase, the total microbial count was nearly constant (about $10^{8}$ to $10^{9}$ cells/g-dry sediment) except for a slight decrease a week after the application. The CFU tended to decrease slightly with time, but was nearly constant as well. In the aqueous
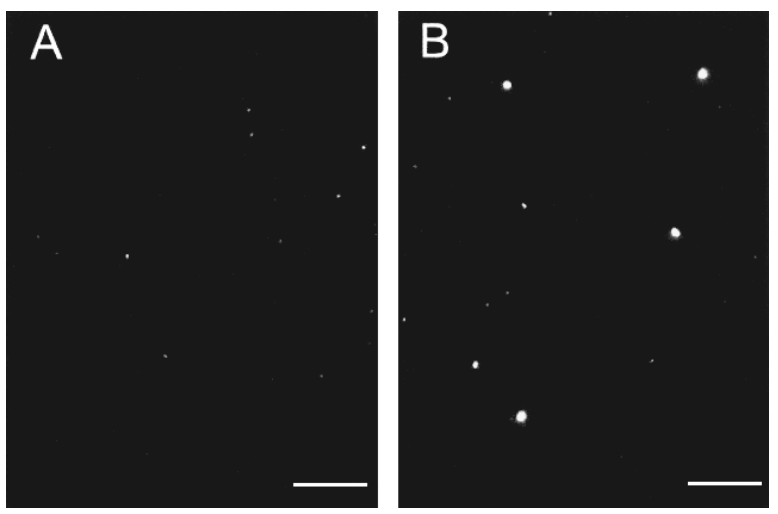

Fig. 5. Representative microscopic images of microbes in aqueous phase of microcosm PC-1.

A: time-0 (immediately before application of atrazine).

B: Day-49. Bar, $10 \mu \mathrm{m}$.

phase, the total microbial counts fluctuated between $5 \times 10^{5}$ and $10^{6}$ cells $/ \mathrm{ml}$, but the increase and decrease seemed to have no specific tendency. On the other hand, the CFU value gradually increased with time after a transient decrease until Day-14. The CFU number at Day-49, when atrazinedegradation was proceeding very rapidly, reached about 10 times the minimum number (Day-14). However, this increase seemed not to reflect the degrading activity, because we obtained no atrazine-degradable microbial strains from more than 80-isolated colonies on Day-49.

\section{Growth and behavior of degrading microbes}

By comparison of the results from each microcosm, as Hattori et al. ${ }^{13,14)}$ have shown, the following mechanism could be considered for microbial growth and behavior: The cells that potentially degrade atrazine would increase gradually on the surface of sediment particles at first, and some of the daughter cells would be detached in the water phase, as observed in microcosm PC-3, in which atrazine degradation proceeded without sediment. Figure 5 shows representative microscopic images of the aqueous phase at time-0 (immediately before application) and Day-49. At Day-49, large, glittering and whole particles were recognized under the microscope by DAPI-staining. These particles were speculated to be microbial cells based on the observation in our additional experiment: They appeared temporarily, only when the rapid degradation of atrazine proceeded, and were not observed in the non-applied control microcosm. The particles might be important to the primary degradation of atrazine to cyanuric acid. 


\section{References}

1) Behki, R.M. and S.U. Khan. 1986. Degradation of atrazine by Pseudomonas: N-dealkylation and dehalogenation of atrazine and its metabolites. J. Agric. Food Chem. 34: 746-749.

2) Brockway, D.L., J. Hill IV, J.R. Maudsley and R.R. Lassiter. 1979. Development, replicability and modeling of naturally derived microcosms. Intern. J. Environmental Studies 13: 149-158.

3) Cook, A.M. 1987. Biodegradation of $s$-Triazine xenobiotics. FEMS Microbiol. Rev. 46: 93-116.

4) Cook, A.M., P. Beilstein, H. Grossenbacher and R. Hutter. 1985. Ring cleavage and degradative pathway of cyanuric acid in bacteria. Biochem. J. 231: 25-30.

5) Cook, A.M. and R. Hutter. 1981. s-Triazines as nitrogen sources for bacteria. J. Agric. Food Chem. 29: 1135-1143.

6) Cook, A.M. and R. Hutter. 1984. Deethylsimizine: bacterial dechlorination, deamination, and complete degradation. J. Agric. Food Chem. 32: 581-587.

7) De Souza, M.L., D. Newcombe, S. Alvey, D.E. Crowley, A. Hay, M.J. Sadowsky and L.P. Wackett. 1998. Molecular basis of a bacterial consortium: interspecies catabolism of atrazine. Appl. Environ. Microbiol. 64: 178-184.

8) Dousset, S., C. Mouvet and M. Schiavon. 1997. Degradation of $\left[{ }^{14} \mathrm{C}\right]$ terbuthylazine and $\left[{ }^{14} \mathrm{C}\right]$ atrazine in laboratory soil microcosms. Pestic. Sci. 49: 9-16.

9) Ferris, I.G. and E.P. Lichtenstein. 1980. Interactions between agricultural chemicals and soil microflora and their effects on the degradation of $\left[{ }^{14} \mathrm{C}\right]$ parathion in a cranberry soil. J. Agric. Food Chem. 28: 1011-1019.

10) Fish, M. and J.M. Principe. 1994. Biotransformation of aroclor 1242 in Hudson River test tube microcosms. Appl. Environ. Microbiol. 60: 4289-4296.

11) Fuma, S., H. Takeda, K. Miyamoto, K. Yanagisawa, Y. Inoue, N. Ishii, K. Sugai and C. Ishii. 2000. Simple aquatic microcosm for ecotoxicity screening at the community level. Bull. Environ. Contam. Toxicol. 65: 699-706.

12) Giddings, J.M. and G.K. Eddlemon. 1977. The effects of microcosm size and substrate type on aquatic microcosm behavior and arsenic transport. Arch. Environ. Contam. Toxicol. 6: 491-505.

13) Hattori, R., T. Hattori and C. Furusaka. 1972. Growth of bacteria on the surface of anion-exchange resin. Experiment with batch culture. J. Gen. Appl. Microbiol. 18: 271-283.

14) Hattori, R., T. Hattori and C. Furusaka. 1972. Growth of bacteria on the surface of anion-exchange resin. II Electron microscope observation of adsorbed cells growing on resin surface by carbon replica method. J. Gen. Appl. Microbiol. 18: 285-293.

15) Hobbie, J.E., R.J. Daley and S. Jasper. 1977. Use of nuclepore filters for counting bacteria by fluorescence microscopy. Appl. Environ. Microbiol. 33: 1225-1228.

16) Holm, P.E., P.H. Nielsen, H.-J. Albrechtsen and T.H. Christensen. 1992. Importance of unattached bacteria and bacteria attached to sediment in determining potentials for degradation of xenobiotic organic contaminants in an aerobic aquifer. Appl. Environ. Microbiol. 58: 3020-3026.

17) Ibekwe, A.M., S.K. Papiernik, J. Gan, S.R. Yates, C.H. Yang and D.E. Crowley. 2001. Impact of fumigants on soil microbial communities. Appl. Environ. Microbiol. 67: 3245-3257.

18) Jones, T.W., W.M. Kemp, J.C. Stevenson and J.C. Means. 1982.
Degradation of atrazine in estuarine water/sediment and soils. J. Environ. Qual. 11: 632-638.

19) Kepner, Jr., R.L. and J.R. Pratt. 1994. Use of fluorochromes for direct enumeration of total bacteria in environmental samples: past and present. Microbiol. Rev. 58: 603-615.

20) Kuwae, T. and Y. Hosokawa. 1999. Determination of abundance and biovolume of bacteria in sediments by dual staining with 4',6-diamidino-2-phenylindole and acridine orange: relationship to dispersion treatment and sediment characteristics. Appl. Environ. Microbiol. 65: 3407-3412.

21) Lehman, R.M. and S.P. O'Connell. 2002. Comparison of extracellular enzyme activities and community composition of attached and free-living bacteria in porous medium columns. Appl. Environ. Microbiol. 68: 1569-1575.

22) Muller, S.R., M. Berg, M.M. Ulrich and R.P. Schwarzenbach. 1997. Atrazine and its primary metabolites in Swiss lakes: input characteristics and long-term behavior in the water column. Environ. Sci. Technol. 31: 2104-2113.

23) Organization for Economic Cooperation and Development (OECD): Guidelines for testing of chemicals. 1997. Aerobicanaerobic transformation in water-sediment systems (draft proposal).

24) Panshin, S.Y., D.S. Carter and E.R. Bayless. 2000. Analysis of atrazine and four degradation products in the pore water of the vadose zone, central India. Environ. Sci. Technol. 34: 21312137.

25) Porter, K.G. and Y.S. Freig. 1980. The use of DAPI for identifying and counting aquatic microflora. Limnol. Oceanogr. 25: 943 948.

26) Pratt, J.R., N.J. Bowers, B.R. Niederlehner and J. Cairns, Jr. 1988. Effects of atrazine on freshwater microbial communities. Arch. Environ. Contam. Toxicol. 17: 449-457.

27) Radosevich, M., S.J. Traina, Y.L. Hao and O.H. Tuovinen. 1995. Degradation and mineralization of atrazine by a soil bacterial isolate. Appl. Environ. Microbiol. 61: 297-302.

28) Ramirez-Saad, H.C., A. Sessitsch, W.M. de Vos and A.D. Akkermans. 2000. Bacterial community changes and enrichment of Burkholderia-like bacteria induced by chlorinated benzoates in a peat-forest soil-microcosm. Syst. Appl. Microbiol. 23: 591598.

29) Satsuma, K., H. Nakamura, K. Sato and Y. Kato. 2001. A negative effect of co-solvent on atrazine biodegradation in experimental river microcosms. Microbes and Environment 16: 185-189.

30) Simon, M. 1985. Specific uptake rates of amino acids by attached and free-living bacteria in a mesotrophic lake. Appl. Environ. Microbiol. 49: 1254-1259.

31) Sugiura, K. 1992. A multispecies laboratory microcosm for screening ecotoxicological impacts of chemicals. Eviron. Toxicol. Chem. 11: 1217-1226.

32) Takagi, H., M. Hashimoto, Y. Takamatsu and Y. Inamori. 1994. Assessment of effect of herbicides on aquatic ecosystem using small-scale microcosm systems. Mizukankyogakkaishi 17: 650660 (in Japanese).

33) U.S. Environmental Protection Agency: Fate, transport and transformation test guidelines. 1998. Sediment/water microcosm biodegradation test. OPPTS 835.3180.

34) Van Veld, P.A. and J.C. Spain. 1983. Degradation of selected xenobiotic compounds in three types of aquatic test systems. Chemosphere 12: 1291-1305. 